\title{
Hospital Costs for Preterm and Small-for-Gestational Age Babies in Canada
}

\author{
Gillian Lim, Jacinth Tracey, Nicole Boom, Sunita Karmakar, Joy Wang, Jean-Marie Berthelot and Caroline Heick
}

\begin{abstract}
In 2006-2007, more than 54,000 (or one in seven) babies across Canada were born preterm or small for their gestational age (SGA). These babies are often at higher risk for morbidity and mortality than are full-term babies with normal birth weight, and account for a disproportionately high percentage of healthcare costs among newborns. This article highlights key findings from a recent report by the Canadian Institute for Health Information, Too Early, Too Small: A Profile of Small Babies across Canada, and provides information on the hospital costs among low birth weight, preterm and SGA babies. Birth weight and gestational age were found to be important determinants of hospital costs - as birth weight and gestational age decreased, average in-hospital costs increased. Furthermore, multiple-birth babies had higher hospital costs than did singleton babies. As in other areas of the health system, information relating to costs and spending can inform neonatal and obstetrical health planning and decision-making.
\end{abstract}

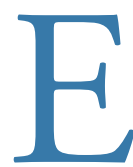

ach year, approximately 350,000 babies are born in Canada. Although most (over 90\%) of these babies are born with a normal birth weight $(2,500-4,499$ grams), about $6 \%$ are born with low birth weight $(<2,500$ grams) (Statistics Canada 2008). Low birth weight may result from a preterm birth $(<37$ weeks of gestation), intrauterine growth restriction (IUGR) or both (Institute of Health Economics 2007). The diagnosis of IUGR is typically based on a baby being small for gestational age (SGA) - meaning that it is smaller than $90 \%$ of babies of the same gestational age and sex. In 2006-2007, more than 54,000 (one in seven) babies across Canada were born preterm or SGA.

Babies who are born preterm or SGA are often at higher risk for morbidity and mortality than are full-term babies with normal birth weight. These differential health consequences can extend far beyond infancy and childhood (Das and Sysyn 2004; Saigal and Doyle 2008) and also impact healthcare costs. Preterm and SGA status account for a disproportionately high percentage of the healthcare costs among all newborns (Russell et al. 2007).
Some researchers have even suggested that economically developed countries should recognize the economic impact of low birth weight on health services planning (Petrou et al. 2003).

This article highlights key findings from a recent report by the Canadian Institute for Health Information (CIHI), Too Early, Too Small: A Profile of Small Babies across Canada (CIHI 2009), and provides information on the hospital costs among low birth weight, preterm and SGA babies.

\section{In 2006-2007, more than 54,000 (one in seven) babies across Canada were born preterm or small for gestational age.}

\section{Variation in Preterm and SGA Rates}

Low birth weight has long been used as an indicator of perinatal (about five months before and one week after birth) health due to its association with infant survival, health and development (United Nations Children's Fund and World Health Organization 2004). Associated risks include perinatal or infant death, physical and cognitive disabilities and chronic health problems later in life (Goldenberg and Culhane 2007). However, low birth weight babies are not a homogeneous group, and there are differences in health outcomes associated with babies who are born preterm or SGA. For this reason, these groups are best considered separately.

Preterm births account for $75 \%$ of deaths that occur in the perinatal period (Goldenberg et al. 2008) and contribute to both short- and long-term morbidity, including respiratory distress, gastrointestinal complications, temperature instability and neuro-cognitive problems (Hack and Fanaroff 1999; Saigal and Doyle 2008). In Canada, as in many other economically developed countries, the preterm birth rate has increased over the past few decades. In 2006-2007, the Canadian preterm birth rate was $8.1 \%$ (CIHI 2009) - up from 6\% in the early 1980s (Joseph et al. 1998). However, this rate varied across the provinces, with Alberta and Newfoundland and Labrador having the highest rates $(8.7 \%$ and $8.6 \%$, respectively) while New Brunswick and 
Prince Edward Island had the lowest (both at 7\%). Nunavut had the highest preterm birth rate overall at 10.8\%.

Unlike preterm birth rates, SGA rates in Canada have decreased over the past few decades - from $11 \%$ in the early 1990s (Health Canada 2003) to $8.3 \%$ in 2006-2007 (CIHI 2009). This rate also varied across the country: Ontario and Alberta had the highest rates $(8.9 \%$ and $8.7 \%$, respectively) while Newfoundland and Labrador and Prince Edward Island had the lowest $5.9 \%$ and $6.8 \%$, respectively). Although the rates have decreased over time, SGA births remain an important health issue as these babies are a high-risk group; the perinatal mortality rate for growth-restricted infants is 10-20 times higher than that among infants who are not growth restricted (Das and Sysyn 2004).

\section{Preterm births account for $75 \%$ of deaths that occur in the perinatal period.}

\section{Cost Drivers: Birth Weight, Gestational Age and Length of Stay}

On average, preterm and SGA babies require special monitoring and care in the first days and weeks of their lives and tend to remain longer in hospital after delivery. Major improvements in neonatal care have contributed to increased survival for babies born preterm or SGA but are also associated with higher healthcare costs.

Preterm infants tend to use more hospital resources than infants who are born full term. Specifically, they often require the use of specialized equipment such as respirators, monitors, intravenous pumps and kidney dialysis equipment, longer lengths of hospital stay and increased healthcare personnel resources (Cuevas et al. 2005). This, in turn, is associated with increased healthcare costs. Moreover, preterm babies are also more likely to be re-hospitalized after the initial discharge (Saigal and Doyle 2008).

Cost estimates presented in this article reflect only the in-patient hospital costs among newborns who received treatment in the hospital in which they were born and discharged (i.e., "typical" newborns). They exclude stillbirths, transfers and patients who stayed longer than the expected length of stay. Further description of the methodology is provided in the report (Canadian Institute for Health Information 2009).

Hospital costs decreased as birth weight increased, with the smallest infants having the highest cost and longest lengths of stay (Figure 1). The average hospital costs per newborn in Canada in 2005-2006 varied widely - ranging from just over $\$ 1,000$ for newborns who weighed 2,500 grams or more, to more than $\$ 117,000$ for newborns who weighed less than 750

Figure 1. Average hospital cost for "typical" newborns, by birth weight category, 2005-2006

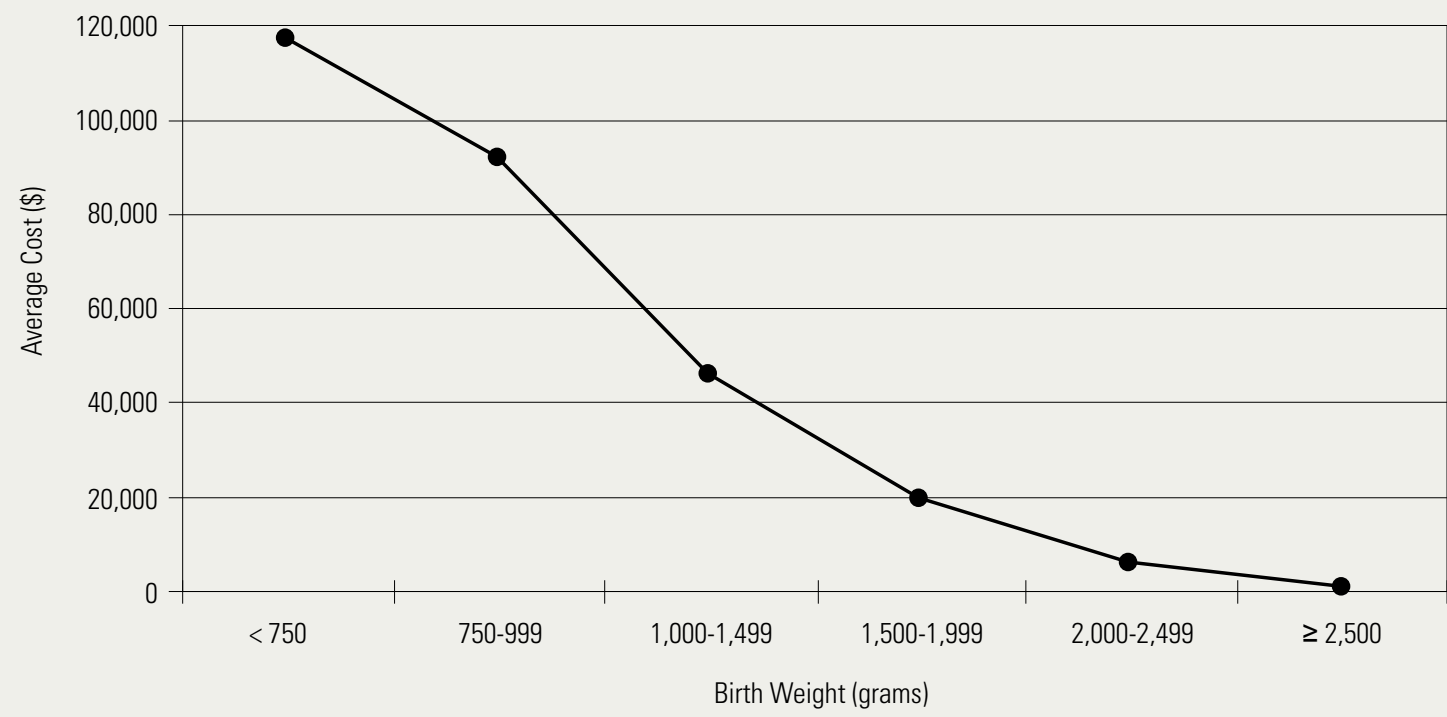

Note: This analysis was restricted to live births discharged from acute care facilities located in Newfoundland and Labrador, Ontario, Manitoba, Saskatchewan, British Columbia and Nunavut.

Sources: Discharge Abstract Database, 2005-2006, and Canadian MIS (Management Information Systems) Database, 2005-2006, Canadian Institute for Health Information 
Table 1. Average hospital costs and length of stay for "typical" newborns by multiple birth and gestational age category, 2005-2006*

\begin{tabular}{|c|c|c|c|c|}
\hline Multiple Birth Status by Preterm Status & Total No. Babies & \% Typical & Average Cost & Average LOS \\
\hline \multicolumn{5}{|l|}{ Singletons } \\
\hline Full term ( $\geq 37$ wk) & 189,750 & 97.6 & 1,050 & 2.1 \\
\hline Any preterm (<37 wk) & 13,005 & 79.2 & 9,233 & 10.0 \\
\hline Late preterm (34-36 wk) & 9,716 & 89.7 & 5,047 & 5.8 \\
\hline Moderate preterm (32-33 wk) & 1,428 & 69.1 & 19,463 & 21.2 \\
\hline Very preterm (28-31 wk) & 1,099 & 42.3 & 43,718 & 42.6 \\
\hline Extremely preterm ( $<28 w k)$ & 762 & 18.1 & 84,235 & 83.1 \\
\hline Total & 202,755 & 96.4 & 1,482 & 2.5 \\
\hline \multicolumn{5}{|l|}{ Multiples } \\
\hline Full term ( $\geq 37$ wk) & 2,742 & 95.7 & 1,871 & 3.5 \\
\hline Any preterm (<37 wk) & 3,623 & 70.9 & 12,479 & 13.8 \\
\hline Late preterm (34-36 wk) & 2,370 & 85.9 & 6,494 & 8.0 \\
\hline Moderate preterm (32-33 wk) & 571 & 57.3 & 21,388 & 23.5 \\
\hline Very preterm (28-31 wk) & 418 & 38.0 & 47,318 & 46.0 \\
\hline Extremely preterm (<28 wk) & 264 & 18.2 & 90,123 & 91.0 \\
\hline Total & 6,365 & 81.6 & 7,118 & 8.6 \\
\hline
\end{tabular}

LOS = length of stay.

*This analysis was limited to live births discharged from acute care facilities located Newfoundland and Labrador, Ontario, Manitoba, Saskatchewan, British Columbia and Nunavut.

Sources: Discharge Abstract Database, 2005-2006, and Canadian MIS (Management Information Systems) Database, 2005-2006, Canadian Institute for Health Information. birth baby. As well, the average hospital cost for multiples was consistently higher than for singletons for each gestational age category. This may reflect the increased likelihood of preterm birth, SGA birth and medical interventions among multiple births (Cassell et al. 2004).

In 2005-2006, the average hospital cost for all singleton SGA infants was approximately 1.6 times higher than for non-SGA infants $(\$ 2,297$ versus $\$ 1,407$, respectively; Table 2). Poorer health outcomes and subsequent costs associated with SGA babies may vary depending on the underlying mechanism and timing of the growth-restriction onset. Babies who are growth restricted are at an increased risk of fetal distress during labour (Das and Sysyn 2004; Rosenberg 2008) and have higher rates of Cesarean section deliv- grams. Similarly, in analyses not shown here, the average length of hospital stay for typical newborns increased as birth weight decreased - ranging from two days for babies weighing 2,500 grams or more, to 104 days for those less than 750 grams.

In 2005-2006, the average hospital cost for typical singleton newborns was approximately nine times higher for preterm newborns than for those born full-term (Table 1). The average hospital cost and length of stay increased with decreasing gestational age. Singleton newborns born at extremely preterm gestational ages ( $<28$ weeks) had the highest average cost $(\$ 84,235)$ and stayed in the hospital an average of 40 times longer than singletons born at full-term.

Preterm multiple-birth babies had a cost approximately seven times higher than the average cost for a full-term multiple- eries and inductions of labour (Cunningham et al. 2005). Note, however, that costs for these interventions were not captured since this analysis did not include maternal costs.

Among singletons, newborns who were born both preterm and SGA had almost twice the average hospital cost compared with costs for normal-growth preterm newborns ( $\$ 8,558$ versus $\$ 16,244)$. This suggests that poor growth is an additional risk for poor neonatal outcomes beyond that caused by preterm birth (Gilbert and Danielsen 2003). The higher average cost observed for each gestational age category for SGA infants compared with non-SGA infants may be explained by the increased complexity and severity of the medical problems faced by SGA infants compared with those who had normal growth during pregnancy (Sharma et al. 2004). 
Table 2. Average hospital cost and length of stay for "typical" singleton newborns by SGA status and gestational age category, 2005-2006*

\begin{tabular}{|l|c|c|c|c|}
\hline SGA Status by Preterm Status & Total No. Babies & \% Typical & Average Cost & Average LOS \\
\hline Not SGA \\
\hline Full term ( $\geq \mathbf{3 7}$ wk) & 173,806 & 97.7 & 1,011 & 2.1 \\
\hline Any preterm (<37 wk) & 11,718 & 80.2 & 8,558 & 9.5 \\
\hline Late preterm (34-36 wk) & 8,778 & 90.3 & 4,383 & 5.3 \\
\hline Moderate preterm (32-33 wk) & 1,307 & 69.8 & 18,571 & 20.3 \\
\hline Very preterm (28-31 wk) & 1,006 & 43.1 & 41,347 & 42.0 \\
\hline Extremely preterm (<28 wk) & 627 & 20.3 & 85,103 & 84.4 \\
\hline Total & 185,524 & 96.6 & 1,407 & 2.5 \\
\hline SGA & & & & \\
\hline Full term ( $\geq 37$ wk) & 15,920 & 96.7 & 1,479 & 2.4 \\
\hline Any preterm (<37 wk) & 1,215 & 74.3 & 16,244 & 15.0 \\
\hline Late preterm (34-36 wk) & 938 & 84.2 & 11,704 & 11.2 \\
\hline Moderate preterm (32-33 wk) & 120 & 62.5 & 30,309 & 31.7 \\
\hline Very preterm (28-31 wk) & 93 & 33.3 & 76,907 & 52.1 \\
\hline Extremely preterm (<28 wk) & 64 & 10.9 & 109,286 & 99.0 \\
\hline Total & 17,135 & 95.1 & 2,297 & 3.1 \\
\hline
\end{tabular}

LOS = length of stay; $S G A=$ small for gestational age .

*This analysis was limited to singleton live births with gestational age between 22 and 43 weeks, who were discharged from acute care facilities located in Newfoundland and Labrador, Ontario, Manitoba, Saskatchewan, British Columbia and Nunavut.

Sources: Discharge Abstract Database, 2005-2006, and Canadian MIS (Management Information Systems) Database, 2005-2006, Canadian Institute for Health Information.

\section{Conclusion}

Our analyses show that birth weight and gestational age are important determinants of hospital costs. As birth weight and gestational age decreased, average in-hospital costs increased. Furthermore, multiple-birth babies had higher hospital costs than did singleton babies, and babies who were born preterm or SGA incurred more costs than did babies who were neither. In Canada and many other economically developed countries, rates of low birth weight and preterm births have increased over time. These babies tend to use disproportionately more hospital resources than do normal birth weight babies. As in other areas of the health system, information relating to costs and spending can inform neonatal and obstetrical health planning and decision-making. HQ

\section{References}

Canadian Institute for Health Information. 2009. Too Early, Too Small: A Profile of Small Babies across Canada. Ottawa, ON: CIHI.

Cassell, K.A., C.M. O'Connell and T.F. Baskett. 2004. "The Origins and Outcomes of Triplet and Quadruplet Pregnancies in Nova Scotia: 1980 to 2001." American Journal of Perinatology 21(8): 439-45.

Cuevas, K.D., D.R. Silver, D. Brooten, J.M. Youngblut and C.M. Bobo. 2005. "The Cost of Prematurity: Hospital Charges at Birth and Frequency of Rehospitalizations and Acute Care Visits over the First Year of Life: A Comparison by Gestational Age and Birth Weight." American Journal of Nursing 105(7): 56-64.

Cunningham, F.G, K.J. Leveno, S.L. Bloom, J.C. Hauth, L.C. Gilstrap III and K.D. Wenstrom. 2005. Williams Obstetrics. New York: McGraw-Hill Professional.

Das, U.G. and G.D. Sysyn. 2004. "Abnormal Fetal Growth: Intrauterine Growth Retardation, Small for Gestational Age, Large for Gestational Age." Pediatric Clinics of North America 51(3): 639-54.

Gilbert, W.M. and B. Danielsen. 2003. "Pregnancy Outcomes Associated with Intrauterine Growth Restriction." American Journal of Obstetrics and Gynecology 188(6): 1596-601.

Goldenberg, R.L. and J.F. Culhane. 2007. "Low Birth Weight in the United States." American Journal of Clinical Nutrition 85(2): 584S-90S.

Goldenberg R.L., J.F. Culhane, J.D. Iams and R. Romero. 2008. "Epidemiology and Causes of Preterm Birth." Lancet 371(9606): 75-84.

Hack, M. and A.A. Fanaroff. 1999. "Outcomes of Children of Extremely Low Birthweight and Gestational Age in the 1990's.” Early Human Development 53(3): 193-218.

Health Canada. 2003. Canadian Perinatal Health Report, 2003. Ottawa, ON: Minister of Public Works and Government Services Canada.

Institute of Health Economics. 2007. "Consensus Statement on Healthy Mothers - Healthy Babies: How to Prevent Low Birth Weight." International Journal of Technology Assessment in Health Care 23(4): 505-14.

Joseph, K.S., M.S. Kramer, S. Marcoux, A. Ohilsson, S.W. Wen, A.C. Allen and R.W. Platt. 1998. "Determinants of Preterm Birth Rates in 
Canada from 1981 through 1983 and from 1992 through 1994.” New England Journal of Medicine 339(20): 1435-39.

Petrou, S., Z. Mehta, C. Hockley, P. Cook-Mozaffari, J. Henderson and M. Goldacre. 2003. "The Impact of Preterm Birth on Hospital Inpatient Admissions and Costs during the First 5 Years of Life." Pediatrics 112(6): 1290-97.

Rosenberg, A. 2008. “The IUGR Newborn.” Seminars in Perinatology 32(3): 219-24.

Russell, R.B., N.S. Green, C.A. Steiner, S. Meikle, J.L. Howse, K. Poschman, T. Dias, L. Potetz, M..J. Davidoff, K. Damus and J.R. Petrini. 2007. "Cost of Hospitalization for Preterm and Low Birth Weight Infants in the United States." Pediatrics 120(1): e1-e9. Retrieved June 9, 2008. <http://pediatrics.aappublications.org/cgi/ content/abstract/120/1/e1?etoc $>$.

Saigal, S. and L.W. Doyle. 2008. "An Overview of Mortality and Sequelae of Preterm Birth from Infancy to Adulthood." Lancet 371(9608): 261-69.

Sharma, P., K. McKay, T.S. Rosenkrantz and N. Hussain. 2004. "Comparisons of Mortality and Pre-discharge Respiratory Outcomes in Small-for-Gestational-Age and Appropriate-for-Gestational-Age Premature Infants." BMC Pediatrics 4(9). Retrieved August 11, 2008. <http://www.biomedcentral.com/content/pdf/1471-2431-4-9.pdf>.

Statistics Canada. 2008. Births 2006 (Catalogue No. 84F0210X). Ottawa, ON: Statistics Canada.

United Nations Children's Fund and World Health Organization. 2004. Low Birthweight: Country, Regional and Global Estimates. New York: UNICEF.

\section{About the Authors}

Gillian Lim, BSc, MSc, is the program lead for analytical products; as such she leads and coordinates the production of analytical products such as theme reports and online hospitalization statistics within the Canadian Institute for Health Information (ClHI).

Jacinth Tracey, BSc, BA, MA, is the manager of decision support services and analytical products, $\mathrm{ClHI}$; she is responsible for providing direction and producing analytical products that focus primarily on data from the Clinical Administrative Databases.

Nicole Boom, BSc, MSc, was an analyst in analytical products, $\mathrm{ClHI}$, and provided methodological and analytical support to special focus reports.

Sunita Karmakar, BSc, MHSc, is a senior analyst in analytical products, $\mathrm{ClHI}$, and leads the analysis and development of methodology for special focus reports.

Joy Wang, BHS, MHSc, is an analyst in analytical products, $\mathrm{ClHI}$, and provides methodological and analytical support to special focus reports.

Jean-Marie Berthelot, BSc, is the vice-president of programs and executive director for Quebec and oversees all of CIHI's databases, including related tools, publications and reports. He is also an adjunct professor in the Department of Epidemiology, Biostatistics and Occupational Health at McGill University, in Montreal, Quebec.

Caroline Heick, BA Hons, MBA, is the director of acute and ambulatory care information services and is responsible for $\mathrm{ClHI}$ 's hospital and ambulatory care databases.

\section{Are you a physician leader?}

Increasingly physicians are scen as instrumencal participans in the managemenr of Canadà health care system The Canadian Society of Physician Executives (CSPE) can offer physicians the opportunity to develop the neeessary skills and gain knowledge to exeel as leaders in these management positions.

Who should join

All physician managers, physician exceutives and any other physician interested in enhancing their effectiveness and involvement in system, institutional, organixation or group management.

Benefits of joining

* quarterly CSPE Neteslener - a highly valued information source for Canadian physician exccurives

* CSPE annat meeting - your opportunicy to med face-to-fice with collergoes and learn from one another

" physician management education - developed in collaboration with the Canadian Medical Association's Plyyician

Manager Institute (PMI) to provide you with the latest managenent skills and information

* online QCA progmam - collexgues from around the country can provide answers to your most challenging managemene questions

For more information contact

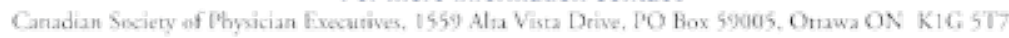

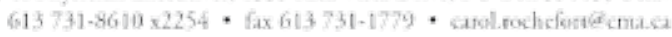

Visit our Web site at www.cspexecs.com 